Jurnal

Kardiologi Indonesia

J Kardiol Indones. 2014;35:272-3

ISSN 0I 26/3773

\title{
A Registry to regionalized treatment of Unstable Angina/ Non-ST Elevation Myocardial Infarction
}

Otte J Rachman

A multicentre Registry to access the current usage of antiplatelet therapy was conducted recently in Indonesia, that can be found in the current edition of this journal. ${ }^{1}$ This was the only registry conducted in Indonesia and this was the only one that try to see the current compliance of the anti-platelet therapy in patients with Unstable Angina / Non-ST Elevation Myocardial Infarction not undergoing PCI procedure in Indonesia. This was very relevant since there is a surge of this diseases in the last decade and more cardiologist worked in the area and also there is more cath lab available to do invasive therapy. Such a facility should be used appropriately and efficiently as not to overburden the available resources both in time and economic aspect, especially in the era of BPJS (universal Health Coverage) which already use up much of these resources.

The BPJS program is an ideal program which give treatment to the majority of people but since the resources is limited it is the duty of the government not to use it indiscriminately and as efficient as possible so it can be delivered to the right people according to its priority. As Indonesia is comprised of large area with thousands of Islands and many population that are devided of many subethnics that are different in many

\section{Alamat Korespondensi}

Dr. Otte J Rachman, Department of Cardiology and Vascular Medicine, University of Indonesia/Harapan Kita National Cardiovascular Center. E-mail: jretto@cbn.net.id aspects, two questions should be answered:

1. Is there any differences in the prevalence of risk factors that are relevant to the development of atherosclerosis

2. Is there any rituals that is relevant or irrelevant for the compliance of patients to any procedure or treatment (including cost)

Since Hypertension, smoking, dyslipidemia and diabetes are the most common risk factors of Coronary Artery Disease, result of the Indonesian Basic Health Survey (RISKESDAS) should be used as guide to give emphasizes on primary prevention according to prevalence of any risk factor in particular area. $^{2}$

This can prevent unnecessary effort in one area that can be better relocated to other area, so regionalization of medical care is more relevant in this setting. Prevention of smoking which is relatively more prevalent especially in younger patients, should be more aggressively managed involving not only the government but the community as well.

The use of GRACE risk score is very useful to discriminate low to moderate risk patients that can be deferred to be sent to catheterization laboratory for PCI (Percutaneous Coronary Intervention) especially for those who were not early enough to reach the hospital. 3

It should be realized that Indonesia is very inhomogeneous population in various aspect and its very logical that we should manage the particular differences of every region according to its specific 
situation. This kind of registry is needed for this country, if we want our effort to be fruitlful for the people that we serve

\section{References}

1. Erwinanto, Widya A, Taufik N, Diniharis S, Kaunang D, Setiawati A. Guideline Compliance in the management of Patients with Unstable Angina/Non ST elevation Myovcardial Infarction without PCI Procedure (medically Managed Registry). Indonesian Journal of Cardiology-current edition

2. The National Institute of Health Research and Development, Ministry of Health, Republic of Indonesia. Repost on Result of National Basic Health Research (RISKESDAS) 2007

3. Eagle KA, Lim DJ, Dabbous OH et al. for the GRACE investigators. A Validated prediction model for all forms of Acute Coronary Syndrome: estimating the risk of 6 month postdischarge death in an International Registry. J Am Med Assoc 2004: 291:2727-2733 